\title{
Quantitative Analysis of Amyloid Deposition in Alzheimer Disease Using PET and the Radiotracer ${ }^{11} \mathrm{C}-\mathrm{AZD2184}$
}

\author{
Hiroshi Ito ${ }^{1}$, Hitoshi Shimada ${ }^{1}$, Hitoshi Shinotoh ${ }^{1}$, Harumasa Takano $^{1}$, Takeshi Sasaki ${ }^{1}$, Tsuyoshi Nogami ${ }^{1}$, \\ Masayuki Suzuki ${ }^{1}$, Tomohisa Nagashima ${ }^{1}$, Keisuke Takahata ${ }^{1}$, Chie Seki ${ }^{1}$, Fumitoshi Kodaka ${ }^{1}$, Yoko Eguchi ${ }^{1}$, \\ Hironobu Fujiwara ${ }^{1}$, Yasuyuki Kimura ${ }^{1}$, Shigeki Hirano ${ }^{1}$, Yoko Ikoma ${ }^{1}$, Makoto Higuchi ${ }^{1}$, Kazunori Kawamura ${ }^{1}$, \\ Toshimitsu Fukumura ${ }^{1}$, Éva Lindström Bö̈̈ ${ }^{2}$ Lars Farde $^{2}$, and Tetsuya Suhara ${ }^{1}$
}

${ }^{1}$ Molecular Imaging Center, National Institute of Radiological Sciences, Chiba, Japan; and ${ }^{2}$ AstraZeneca Translational Sciences Center, Department of Clinical Neuroscience, Karolinska Institutet, Stockholm, Sweden

Characteristic neuropathologic changes in Alzheimer disease (AD) are amyloid- $\beta$ deposits and neurofibrillary tangles. Recently, a new radioligand for amyloid senile plaques, ${ }^{11} \mathrm{C}$-labeled 5 - $(6-\{$ tertbutyl(dimethyl)silyl]oxy\}-1,3-benzothiazol-2-yl)pyridin-2-amine $\left({ }^{11} \mathrm{C}\right.$ AZD2184), was developed, and it was reported to show rapid brain uptake followed by rapid washout. In this study, ${ }^{11} \mathrm{C}-\mathrm{AZD} 2184$ binding in control subjects and $A D$ patients was examined in more detail by compartment model analysis using a metabolite-corrected arterial input function. The accuracy of simplified quantitative methods using a reference brain region was also evaluated. Methods: After intravenous bolus injection of ${ }^{11} \mathrm{C}-\mathrm{AZD} 2184$, a dynamic PET scan was obtained for $90 \mathrm{~min}$ in 6 control subjects and $8 \mathrm{AD}$ patients. To obtain the arterial input function, arterial blood sampling and high-performance liquid chromatography analysis were performed. Results: Time-activity curves in all brain regions could be described using the standard 2-tissue-compartment model. The total distribution volume ratios to reference region $(D V R)$ in cerebral cortical regions were significantly higher in $A D$ patients than in control subjects. Although there was no conspicuous accumulation of radioactivity in white matter as compared with other amyloid radioligands, DVR values in the centrum semiovale were more than 1 for both control subjects and AD patients, suggesting binding to myelin. The standardized uptake value ratio calculated from integrated time-activity curves in brain regions and the reference region was statistically in good agreement with $D V R$. Conclusion: Although the white matter binding of ${ }^{11} \mathrm{C}-\mathrm{AZD} 2184$ may have some effect on cortical measurement, it can be concluded that the kinetic behavior of ${ }^{11} \mathrm{C}-\mathrm{AZD} 2184$ is suitable for quantitative analysis. The standardized uptake value ratio can be used as a validated measure of ${ }^{11} \mathrm{C}$-AZD2184 binding in clinical examinations without arterial input function.

Key Words: amyloid; Alzheimer; PET; AZD2184

J Nucl Med 2014; 55:932-938

DOI: 10.2967/jnumed.113.133793
A

lzheimer disease (AD) is the most common neurodegenerative disorder. Characteristic neuropathologic changes in AD are amyloid- $\beta$ deposits and neurofibrillary tangles (1). The amyloid cascade hypothesis states that the deposition of amyloid- $\beta$ drives the remaining Alzheimer pathology, for example, formation of neurofibrillary tangles, cell loss, and vascular damage (2). From this perspective, in vivo imaging of amyloid- $\beta$ deposits may contribute to early diagnosis of $\mathrm{AD}$ and serve as a marker for evaluation of disease-modifying drugs. To measure amyloid- $\beta$ deposits by PET, several radiotracers, for example, ${ }^{11} \mathrm{C}$-Pittsburgh compound $\mathrm{B}\left({ }^{11} \mathrm{C}\right.$ PIB) $(3,4)$ and $(E)-4-\left(2-\left(6-\left(2-\left(2-\left(2-{ }^{18}\right.\right.\right.\right.\right.$ F-fluoroethoxy)ethoxy)ethoxy) pyridin-3-yl)vinyl)- $N$-methyl benzenamine (5), have been developed and used for examination of the pathophysiology of AD.

${ }^{11}$ C-labeled 5-(6-\{[tert-butyl(dimethyl)silyl]oxy $\}$-1,3-benzothiazol-2-yl)pyridin-2-amine $\left({ }^{11} \mathrm{C}-\mathrm{AZD} 2184\right)$ is a more recently developed radiotracer for amyloid- $\beta$ deposits. ${ }^{11} \mathrm{C}-\mathrm{AZD} 2184$ has been characterized in preclinical studies and has high affinity in vitro for amyloid fibrils (dissociation constant, $8.4 \pm 1.0 \mathrm{nM}$ ) (6). After intravenous injection of ${ }^{11} \mathrm{C}-\mathrm{AZD} 2184$ in an initial human study, there was rapid uptake of radioactivity in the brain, followed by rapid washout in control subjects and in AD patients (7). The ratios of uptake in cortical regions to a reference brain region devoid of amyloid- $\beta$ deposition were close to unity in control subjects and high in AD patients. In addition, there was no conspicuous accumulation of radioactivity in white matter.

The initial results indicate that ${ }^{11} \mathrm{C}-\mathrm{AZD} 2184$ has potential as a sensitive imaging biomarker for research on the pathophysiology and treatment of $\mathrm{AD}$. The aim of the present study was to examine ${ }^{11} \mathrm{C}$-AZD2184 binding in greater detail by compartment model analysis using a metabolite-corrected arterial input function. The accuracy of simplified quantitative methods using a reference brain region was also evaluated.

\section{MATERIALS AND METHODS}

\section{Subjects}

Six control subjects (mean age $\pm \mathrm{SD}, 65 \pm 10 \mathrm{y}$ ) and $8 \mathrm{AD}$ patients $(72 \pm 12 \mathrm{y})$ were recruited (Table 1$)$. All AD patients were diagnosed according to the criteria of the National Institute of Neurologic and Communicative Diseases and Stroke/Alzheimer Disease and Related Disorders Association (8). All subjects were characterized according to the Clinical Dementia Rating scale (9). The control subjects were rated as 0 by the Clinical Dementia Rating scale, whereas the AD subjects were rated as 0.5, 1, or 2. In addition, the Mini-Mental State Examination was performed in 
TABLE 1

Profiles of Subjects

\begin{tabular}{|c|c|c|c|c|c|}
\hline Subject group & Subject no. & Age (y) & Sex & $\begin{array}{l}\text { Mini-Mental State } \\
\text { Examination score }\end{array}$ & $\begin{array}{c}\text { Clinical Dementia } \\
\text { Rating scale }\end{array}$ \\
\hline \multirow[t]{6}{*}{ Control } & NC1 & 61 & $\mathrm{~F}$ & 28 & 0 \\
\hline & NC2 & 51 & $\mathrm{M}$ & 29 & 0 \\
\hline & NC3 & 60 & $\mathrm{M}$ & 30 & 0 \\
\hline & NC4 & 74 & $\mathrm{M}$ & 29 & 0 \\
\hline & NC5 & 71 & $\mathrm{M}$ & 28 & 0 \\
\hline & NC6 & 75 & $\mathrm{~F}$ & 29 & 0 \\
\hline \multirow[t]{8}{*}{$A D$} & AD1 & 76 & $\mathrm{~F}$ & 15 & 1 \\
\hline & AD2 & 55 & $\mathrm{~F}$ & 24 & 1 \\
\hline & AD3 & 63 & $M$ & 13 & 1 \\
\hline & AD4 & 75 & $\mathrm{M}$ & 20 & 0.5 \\
\hline & AD5 & 84 & $\mathrm{~F}$ & 13 & 1 \\
\hline & AD6 & 82 & $\mathrm{~F}$ & 23 & 0.5 \\
\hline & AD7 & 82 & $\mathrm{~F}$ & 19 & 1 \\
\hline & AD8 & 58 & $\mathrm{M}$ & 13 & 1 \\
\hline
\end{tabular}

all subjects (10). No subject had any observable organic brain lesion according to MR imaging. Control subjects had no cognitive impairment and were free from medications for the central nervous system. The study was approved by the Institutional Review Board of the National Institute of Radiologic Sciences, Chiba, Japan. Written informed consent was obtained from all subjects or from their spouses or other close family members.

\section{Radioligand}

${ }^{11} \mathrm{C}$-AZD2184 was produced according to the literature (11). In brief, ${ }^{11} \mathrm{C}-\mathrm{AZD} 2184$ was radiosynthesized by reaction of the precursor 5-(6-(tert-butyldimethyl-silyloxy)benzo[d]thiazol-2-yl)pyridin2-amine with ${ }^{11} \mathrm{C}_{-} \mathrm{CH}_{3} \mathrm{I}$ in the presence of potassium hydroxide and subsequent deprotection by water (7).

\section{PET Experimental Procedure}

All PET measurements were performed with a SET-3000GCT/X scanner (Shimadzu Corp.) (12), which provides 99 sections with an axial field of view of $26 \mathrm{~cm}$. The intrinsic spatial resolution is $3.4 \mathrm{~mm}$

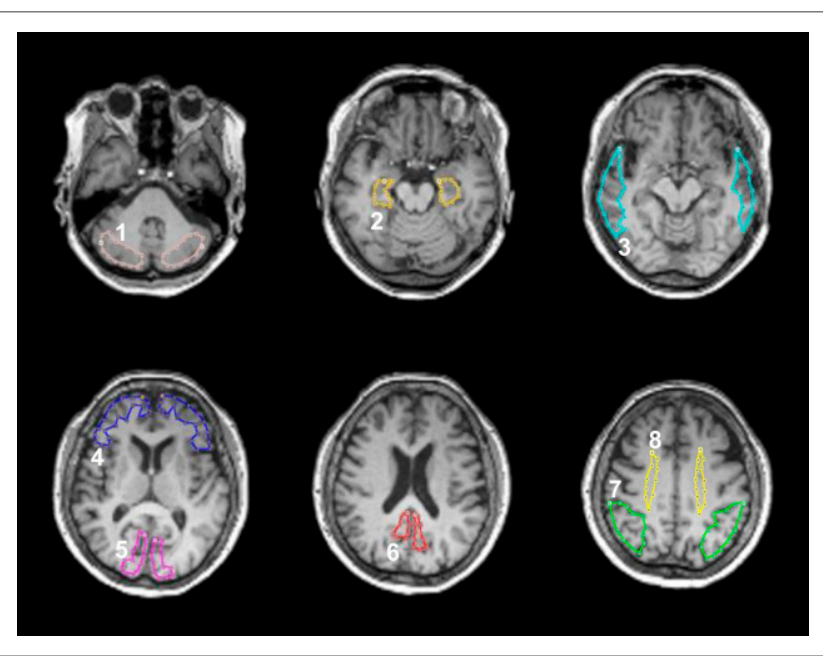

FIGURE 1. ROls drawn on coregistered MR images. ROls are defined for cerebellar cortex (1), parahippocampal gyrus including hippocampus (2), lateral side of temporal cortex (3), base side of frontal cortex (4), cuneus of occipital cortex (5), posterior region of cingulate gyrus (6), parietal cortex (7), and centrum semiovale (8). in-plane and $5.0 \mathrm{~mm}$ in full width at half maximum axially. Images were reconstructed by the filtered backprojection algorithm. With a gaussian filter (cutoff frequency, $0.3 \mathrm{cycle} / \mathrm{pixel}$ ), the reconstructed in-plane resolution was $7.5 \mathrm{~mm}$ in full width at half maximum. Data were acquired in 3-dimensional mode. Scatter correction was done by a hybrid scatter-correction method based on acquisition with dualenergy window setting (13). A 4-min transmission scan using a ${ }^{137} \mathrm{Cs}$ line source was obtained to correct for attenuation.

After intravenous bolus injection of ${ }^{11} \mathrm{C}-\mathrm{AZD} 2184$ over $1 \mathrm{~min}$, a dynamic PET scan was obtained for $90 \mathrm{~min}$. The frame sequence consisted of six 10-s, three 20-s, six 1-min, four 3-min, and fourteen 5-min frames. The radioactivity injected was $380 \pm 12$ and $380 \pm 13 \mathrm{MBq}$, and the specific radioactivity was $131 \pm 38$ and $119 \pm 28 \mathrm{GBq} / \mu \mathrm{mol}$ at the time of injection for control subjects and $\mathrm{AD}$ patients, respectively.

To obtain the arterial input function, 32 samples of arterial blood were taken after injection. The fraction of radioactivity representing unchanged ${ }^{11} \mathrm{C}-\mathrm{AZD} 2184$ in plasma was determined by high-performance

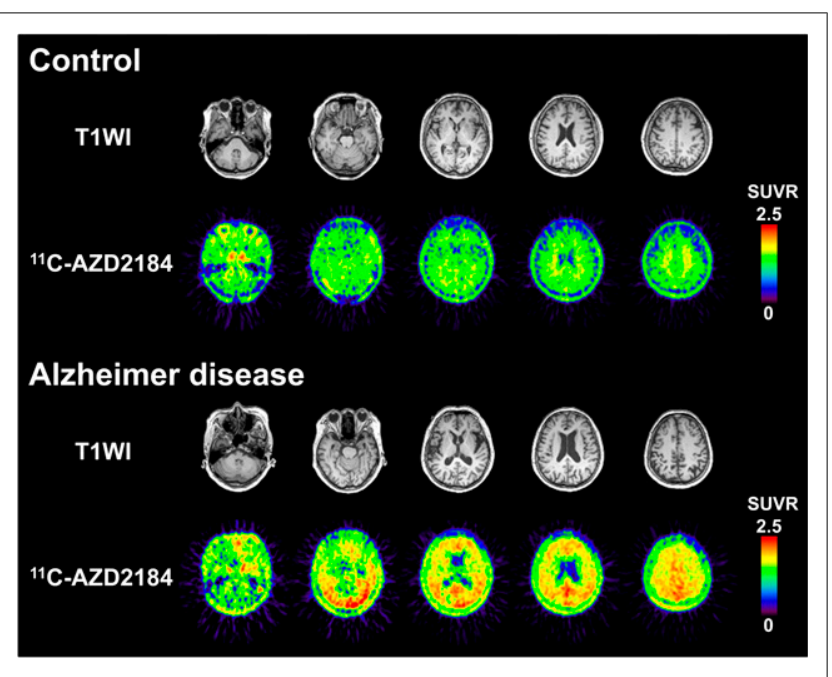

FIGURE 2. Representative SUVR images of ${ }^{11} \mathrm{C}-\mathrm{AZD} 2184$ binding in control subject and AD patient. Integration interval was 40-60 min. Corresponding $M R$ images (T1-weighted [T1WI]) are shown. Scale maximum and minimum values are 2.5 and 0 of SUVR. All images are transaxial sections, and anterior is at top of image and subjects' right is at left. 


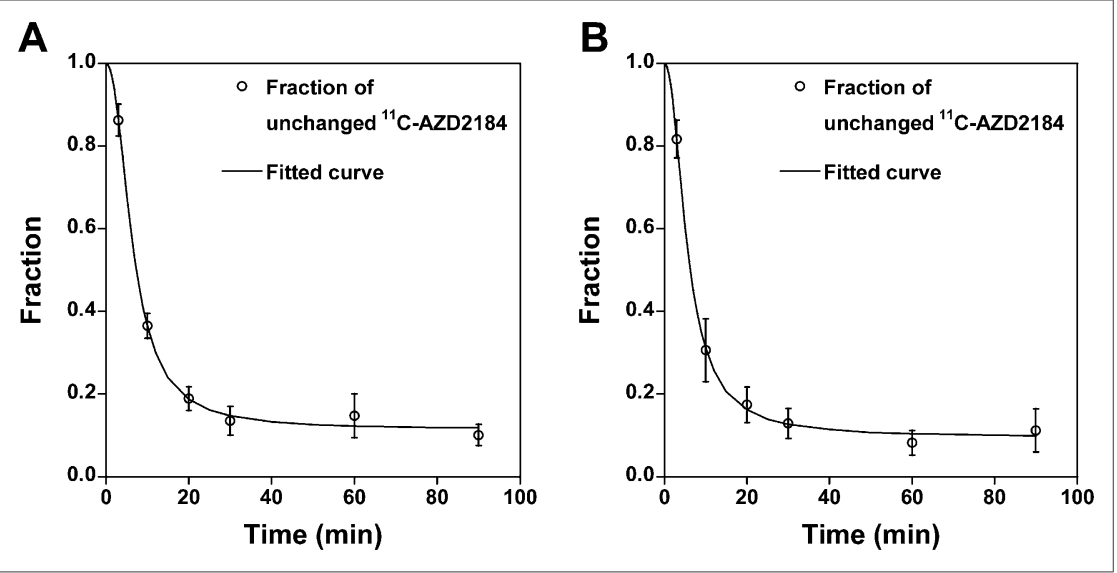

FIGURE 3. Time courses of fraction of radioactivity representing unchanged ${ }^{11} \mathrm{C}-\mathrm{AZD} 2184$ in plasma for control subjects $(A)$ and $A D$ patients $(B)$. Values are mean $\pm S D$. Fitted curves were obtained using Hill equation.

liquid chromatography from 6 blood samples for each subject. Acetonitrile was added to each plasma sample, and the samples were then centrifuged. The obtained supernatant was subjected to radio-highperformance liquid chromatography analysis (column, $\mu$ Bondapak [10 $\mu \mathrm{m}, 7.8 \times 300 \mathrm{~nm}$ ]; Waters) (mobile phase, $90 \%$ acetonitrile [A] $/ 1 \mathrm{~mol} / \mathrm{L}$ ammonium formate [B]; gradient, $0-10 \mathrm{~min}[\mathrm{~A} / \mathrm{B}], 22 / 78$ $47 / 53,10-11 \min [\mathrm{A} / \mathrm{B}], 47 / 53-80 / 20$, and 11-12 $\min [\mathrm{A} / \mathrm{B}], 80 / 20$ 22/78; isocratic, $12-15 \mathrm{~min}$ end; flow rate, $6.0 \mathrm{~mL} / \mathrm{min}$ ). Plasma protein binding was not determined in the present study. The time curves for the fraction of unchanged ${ }^{11} \mathrm{C}$-AZD2184 in plasma were fitted by the Hill equation and used for kinetic analysis.

\section{MR Imaging Procedure}

All MR imaging examinations were performed with a 3-T MR scanner (GE Healthcare). Three-dimensional volumetric acquisition of a T1-weighted 3-dimensional fast spoiled gradient-recalled acquisition in the steady-state sequence produced a gapless series of thin transverse sections (echo time, $2.848 \mathrm{~ms}$; repetition time, $6.992 \mathrm{~ms}$; prep time, $900 \mathrm{~ms}$; flip angle, $8^{\circ}$; field of view, $260 \mathrm{~mm}$; acquisition matrix, $256 \times 256$; slice thickness, $1 \mathrm{~mm}$; scan time, $367 \mathrm{~s}$ ). Proton density-weighted and T2-weighted images were obtained by a 2-dimensional double-echo fast spin echo sequence with interleaved and gapless acquisition (echo time for proton density-weighted images, $10.58 \mathrm{~ms}$; effective echo time for T2weighted images, $95.22 \mathrm{~ms}$; repetition time, $3,000.00 \mathrm{~ms}$; field of view, $240 \mathrm{~mm}$; acquisition matrix, $256 \times 256$; slice thickness, $3 \mathrm{~mm}$ [no gap, interleave]; echo train length, 16; scan time, 309 s). T1-weighted images were used for analysis of PET images. Proton density-weighted and T2-weighted images were used to confirm whether subjects had any observable organic brain lesion.

\section{Regions of Interest (ROIs)}

All MR images were coregistered to the individual PET images using the software package PMOD (version 3.0; PMOD Technologies Ltd.). ROIs were drawn on coregistered MR images (T1-weighted images) and transferred to the PET images. ROIs were defined for the cerebellar cortex, parahippocampal gyrus including the hippocampus, posterior region of the cingulate gyrus, base side of the frontal cortex, lateral side of the temporal cortex, parietal cortex, cuneus of the occipital cortex, and centrum semiovale (Fig. 1). Each ROI was drawn on 3 adjacent sections, and data were pooled to obtain the average radioactivity concentration for the whole volume of interest. To obtain regional time-activity curves, regional radioactivity was calculated for each frame, corrected for decay, and plotted versus time.

\section{Kinetic Model for Interpretation of ${ }^{11} \mathrm{C}$-AZD2184 Binding}

To interpret the kinetic behavior of ${ }^{11} \mathrm{C}-\mathrm{AZD} 2184$, the standard 2tissue-compartment model with 4 first-order rate constants was used (14). The rate constants $K_{1}$ and $k_{2}$ describe the influx and efflux rates for radiotracer diffusion through the blood-brain barrier, respectively. The rate constants $k_{3}$ and $k_{4}$ describe the radiotracer transfer between the compartments for nondisplaceable radiotracer and specific binding. The distribution volume with only nondisplaceable binding in a brain region $\left(V_{\mathrm{ND}}\right)$, the total distribution volume $\left(V_{\mathrm{T}}\right)$, and the binding potential relative to the concentration of nondisplaceable radiotracer in brain $\left(B P_{\mathrm{ND}}\right)$ are expressed as follows $(15)$ :
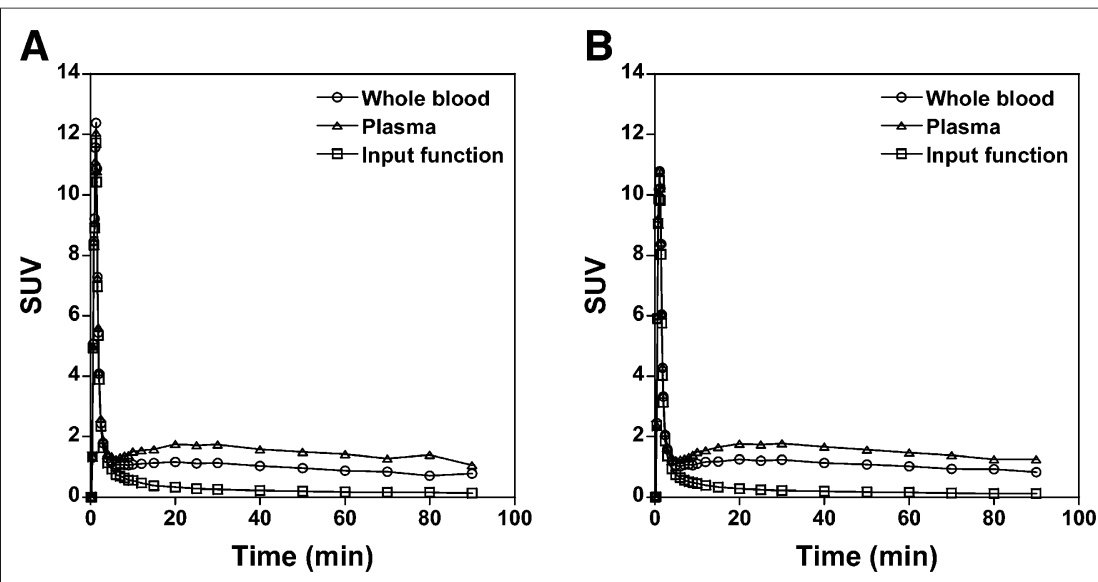

FIGURE 4. Time courses of average radioactivity concentration in arterial whole blood and plasma for control subjects $(A)$ and $A D$ patients $(B)$. Time courses of average radioactivity concentration of unchanged ${ }^{11} \mathrm{C}-\mathrm{AZD} 2184$ in plasma (i.e., arterial input function) are also shown.

$$
\begin{gathered}
V_{\mathrm{ND}}=\frac{K_{1}}{k_{2}} \\
V_{\mathrm{T}}=\frac{K_{1}}{k_{2}}\left(1+\frac{k_{3}}{k_{4}}\right) \\
B P_{\mathrm{ND}}=\frac{k_{3}}{k_{4}}
\end{gathered}
$$

\section{Kinetic Analysis of ${ }^{11} \mathrm{C}$-AZD2184 Binding}

To estimate the rate constants $\left(K_{1}, k_{2}, k_{3}\right.$, and $k_{4}$ ), nonlinear curve fitting was performed in a least-squares sense to the regional time-activity curves (16). In this analysis, the blood volume, which depends on the first-pass extraction fraction of the tracer, was assumed to be $0.04 \mathrm{~mL} / \mathrm{mL}$ to diminish the influence of tracer remaining in the blood using the radioactivity of whole blood (17). The radioactivity of unchanged ${ }^{11} \mathrm{C}-\mathrm{AZD} 2184$ 


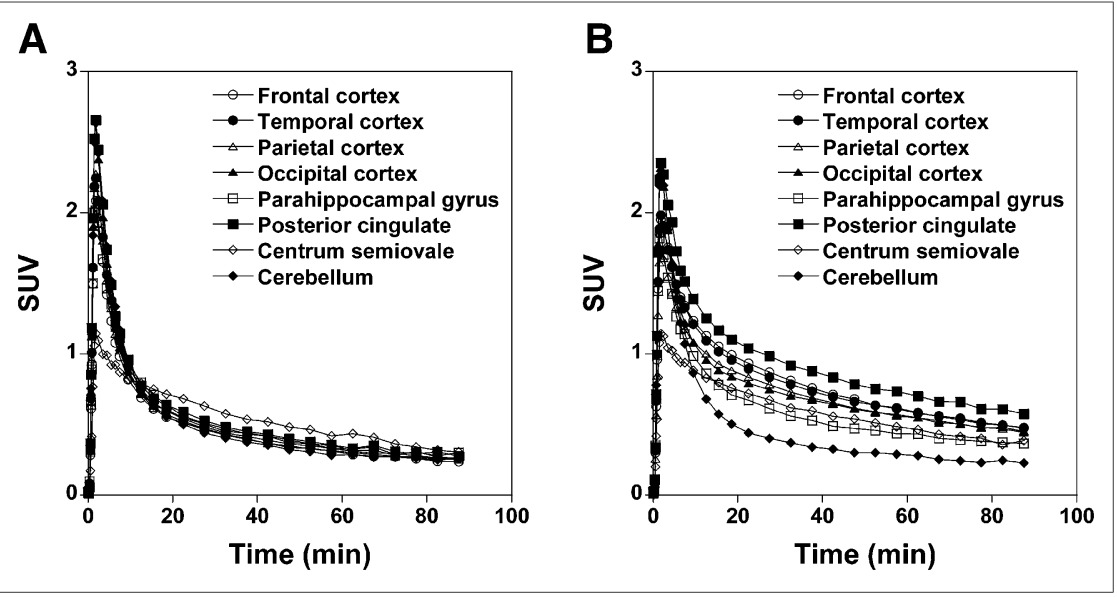

FIGURE 5. Average time-activity curves for brain regions in control subjects $(A)$ and $A D$ patients (B).

in plasma was used as the arterial input function. For this analysis, PMOD was used. $V_{\mathrm{T}}$ was calculated from the rate constants as an indicator of amyloid- $\beta$ deposits (Eq. 2).

\section{Quantitative Approach Using Reference Region}

The cerebellum has been suggested as a reference brain region because no fibrillar amyloid plaques have been demonstrated in this region postmortem $(18,19)$. A quantitative approach, taking advantage of the cerebellum as a reference region, can be used to calculate the total distribution volume ratio $(D V R)$ as follows:

$$
D V R=V_{\mathrm{T}(\text { brain })} / V_{\mathrm{T}(\text { cerebellum })},
$$

where $V_{\mathrm{T}(\text { brain) }}$ and $V_{\mathrm{T} \text { (cerebellum) }}$ are total distribution volume in brain regions and the cerebellum, respectively. The $B P_{\mathrm{ND}}$ is equal to $D V R-$ 1 if the cerebellum is the ideal reference brain region.

In addition, the standardized uptake value $(S U V)$ was calculated from the time-integrated regional radioactivity concentration normalized with injected dose per body weight. The integration intervals were $20-40,40-60$, and $60-90 \mathrm{~min}$. The integration interval of 20 40 min includes the peak equilibrium condition (20), and the integration intervals of 40-60 and 60-90 min correspond to the late part of the time-activity curve. In a simplified approach and because the cerebellum can be used as a reference brain region, the $S U V$ ratio $(S U V R)$ indicating amyloid- $\beta$ deposits was calculated using the following expression:

$$
S U V R=S U V_{\text {brain }} / S U V_{\text {cerebellum }},
$$

where $S U V_{\text {brain }}$ and $S U V_{\text {cerebellum }}$ represent the $S U V$ in brain regions and the cerebellum, respectively.

\section{RESULTS}

In this study, no adverse event was observed after intravenous injection of ${ }^{11} \mathrm{C}$-AZD2184. Representative SUVR images showing the distribution of brain radioactivity after intravenous injection of ${ }^{11} \mathrm{C}$-AZD2184 are shown for a control subject and an AD patient in Figure 2. There was no conspicuous accumulation of radioactivity in white matter, the same as in a previous report (7). In $\mathrm{AD}$ patients, radioactivity in the cerebral cortices was higher than in the control subjects. By visual assessment of the SUVR images, all control subjects appeared negative with regard to specific binding of ${ }^{11} \mathrm{C}$-AZD2184, whereas all AD patients appeared positive.

The time courses for the average fraction of radioactivity representing unchanged ${ }^{11} \mathrm{C}$ AZD2184 in plasma for control subjects and AD patients are shown in Figure 3. Sixty minutes after injection of ${ }^{11}$ C-AZD2184, the fraction of radioactivity representing unchanged ${ }^{11} \mathrm{C}$-AZD2184 in plasma was $0.11-0.12$. The time courses of the average radioactivity concentration in whole blood and plasma and the time course of the radioactivity concentration of unchanged ${ }^{11} \mathrm{C}$ AZD2184 in plasma (i.e., arterial input function) are shown in Figure 4.

The regional time-activity curves for control subjects and AD patients are shown in Figure 5. At 18.5, 37.5, 57.5, and $87.5 \mathrm{~min}$ after injection of ${ }^{11} \mathrm{C}$-AZD2184, the ratios of regional radioactivity of posterior cingulate to cerebellum were $1.14 \pm 0.03,1.21 \pm 0.09,1.27 \pm$ 0.17 , and $1.08 \pm 0.27$ for control subjects and $2.19 \pm 0.22,2.60 \pm$ $0.57,2.55 \pm 0.49$, and $2.52 \pm 0.64$ for $\mathrm{AD}$ patients. In control subjects, radioactivity concentrations in cerebral cortical regions were similar to those for the cerebellum at the end of data acquisition, the same as in a previous report (7). In AD patients, radioactivity concentrations in cerebral cortical regions were higher than in the cerebellum.

Typical time-activity curves in brain regions of an AD patient and the corresponding fitted curves obtained by kinetic analyses are shown in Figure 6. The time-activity curves in all brain regions could be described by the standard 2-tissue-compartment model.

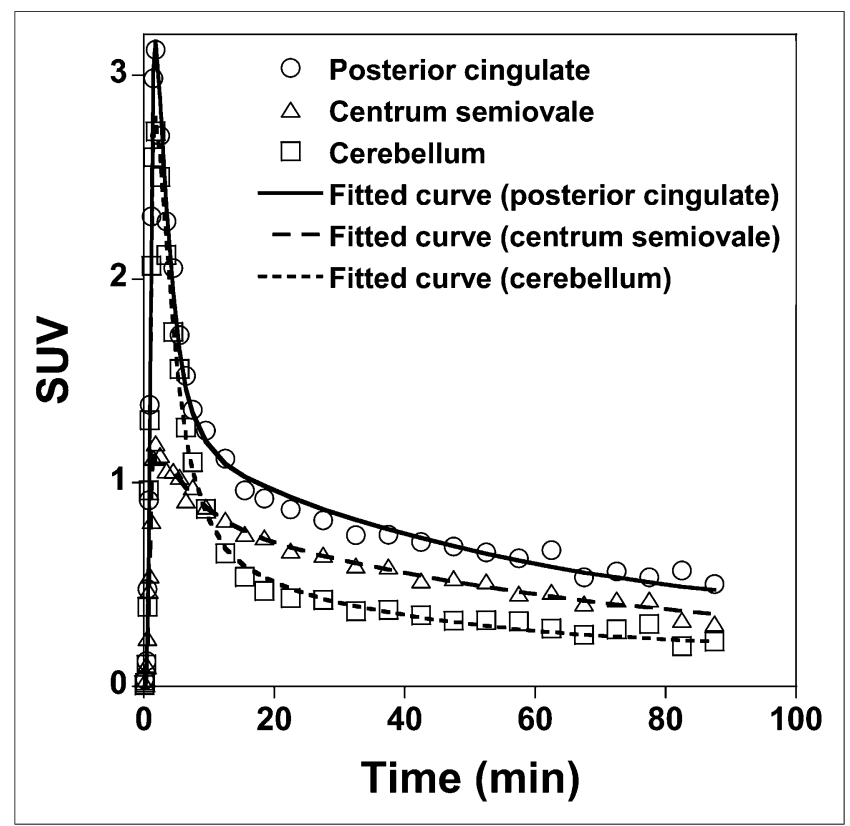

FIGURE 6. Typical time-activity curves in brain regions of $A D$ patient and fitted curves obtained using standard 2-tissue-compartment model. 
TABLE 2

Kinetic Parameters Obtained by 2-Tissue-Compartment Model Analysis of ${ }^{11} \mathrm{C}-\mathrm{AZD} 2184$ Binding in Control Subjects

\begin{tabular}{lcccccc}
\hline \multicolumn{1}{c}{ Brain region } & $K_{1}(\mathrm{~mL} / \mathrm{mL} / \mathrm{min})$ & $k_{2}\left(\mathrm{~min}^{-1}\right)$ & $k_{3}\left(\mathrm{~min}^{-1}\right)$ & $k_{4}\left(\mathrm{~min}^{-1}\right)$ & $V_{\mathrm{T}}(\mathrm{mL} / \mathrm{mL})$ & $D V R$ \\
\hline Frontal cortex & $0.23 \pm 0.07$ & $0.42 \pm 0.09$ & $0.05 \pm 0.02$ & $0.05 \pm 0.02$ & $1.14 \pm 0.19$ & $0.99 \pm 0.07$ \\
Temporal cortex & $0.25 \pm 0.07$ & $0.42 \pm 0.09$ & $0.06 \pm 0.02$ & $0.05 \pm 0.02$ & $1.22 \pm 0.17$ & $1.07 \pm 0.06$ \\
Parietal cortex & $0.25 \pm 0.06$ & $0.43 \pm 0.08$ & $0.05 \pm 0.02$ & $0.05 \pm 0.02$ & $1.18 \pm 0.17$ & $1.03 \pm 0.09$ \\
Occipital cortex & $0.32 \pm 0.07$ & $0.53 \pm 0.12$ & $0.05 \pm 0.02$ & $0.04 \pm 0.01$ & $1.28 \pm 0.17$ & $1.12 \pm 0.09$ \\
Hippocampus & $0.22 \pm 0.05$ & $0.41 \pm 0.12$ & $0.08 \pm 0.04$ & $0.06 \pm 0.02$ & $1.27 \pm 0.19$ & $1.11 \pm 0.07$ \\
Posterior cingulate & $0.32 \pm 0.09$ & $0.52 \pm 0.11$ & $0.06 \pm 0.03$ & $0.06 \pm 0.03$ & $1.33 \pm 0.23$ & $1.16 \pm 0.11$ \\
Centrum semiovale & $0.09 \pm 0.03$ & $0.17 \pm 0.08$ & $0.09 \pm 0.04$ & $0.05 \pm 0.01$ & $1.50 \pm 0.31$ & $1.30 \pm 0.12$ \\
Cerebellum & $0.28 \pm 0.06$ & $0.38 \pm 0.05$ & $0.03 \pm 0.02$ & $0.05 \pm 0.02$ & $1.15 \pm 0.22$ & -
\end{tabular}

Values are mean \pm SD.

The rate constants and related kinetic parameters for ${ }^{11} \mathrm{C}$ AZD2184 binding in control subjects and AD patients are given in Tables 2 and 3, respectively. In control subjects, the $V_{\mathrm{T}}$ in cerebral cortical regions was similar to that in the cerebellum. In $\mathrm{AD}$ patients, $V_{\mathrm{T}}$ values were consistently higher in cerebral cortical regions than in the cerebellum. The $V_{\mathrm{T}}$ and the $D V R$ in cerebral cortical regions were significantly higher in AD patients than in control subjects (unpaired $t$ test, $P<0.01$ ). The $D V R$ in the centrum semiovale was more than 1 in average for both control subjects and $\mathrm{AD}$ patients. No significant differences in $V_{\mathrm{T}}$ and $D V R$ were observed for the centrum semiovale between control subjects and AD patients.

The SUVR and DVR in control subjects and AD patients are shown in Table 4. The SUVR for each integration interval was at the same level and in agreement with the corresponding $D V R$ value. $S U V R$ and $D V R$ in cerebral cortical regions were significantly higher in AD patients than in control subjects. The relationship between $D V R$ and $S U V R$ is shown in Figure 7. Significant correlations were observed between $D V R$ and $S U V R$ for each integration interval.

\section{DISCUSSION}

In the present examination of ${ }^{11} \mathrm{C}-\mathrm{AZD} 2184$ binding to amyloid- $\beta$ deposits, there was high binding in the cerebral cortical regions of $\mathrm{AD}$ patients in comparison with control subjects, the same as in a previous report (7). The $D V R$ values of ${ }^{11} \mathrm{C}-\mathrm{AZD} 2184$ in cerebral cortical regions for both control subjects and $\mathrm{AD}$ patients were almost the same level as those of ${ }^{11} \mathrm{C}-\mathrm{PIB}$ reported previously (18). Although previously developed radioligands, such as ${ }^{11} \mathrm{C}-\mathrm{PIB}$, show high nonspecific binding in white matter, the white matter binding was not conspicuous for ${ }^{11} \mathrm{C}-\mathrm{AZD} 2184$. The $S U V \mathrm{~s}$ in the white matter were less than 0.5 after $60 \mathrm{~min}$ of injection of ${ }^{11} \mathrm{C}-\mathrm{AZD} 2184$ in both control subjects and $\mathrm{AD}$ patients, and those of ${ }^{11} \mathrm{C}$-PIB were reported to be more than 1 (4). The regional time-activity curves could be described by the standard 2-tissue-compartment model. The dissociation rate constant $k_{4}$ was $0.04-0.05 \mathrm{~min}^{-1}$, not zero, indicating reversibility of binding. Thus, it was evident that the kinetic behavior of ${ }^{11} \mathrm{C}$-AZD2184 is similar to that of established neuroreceptor ligands such as ${ }^{11} \mathrm{C}$-raclopride (20) and that this radioligand is likely suitable for quantitative analyses using various established approaches.

The white matter binding of ${ }^{11} \mathrm{C}-\mathrm{AZD} 2184$ appears lower than that reported for other amyloid radioligands such as ${ }^{11} \mathrm{C}-\mathrm{PIB}$ (4), the same as in the previous autoradiographic study with postmortem brain (6). In control subjects, there was no obvious difference between binding in gray and white matter. However, kinetic analysis revealed the $D V R$ to be more than $1(\sim 1.3-1.5)$ in the centrum semiovale, a region that almost entirely consists of white matter, for both control subjects and AD patients. The nature of the binding of amyloid ligand to white matter is not fully understood. It has been reported that ${ }^{11} \mathrm{C}$-PIB may bind to myelin, which is organized in a $\beta$-sheet structure in the same way as amyloid$\beta$ deposits (21-23). The proposed binding has low affinity and is likely not saturable because of the large amount of myelin in the brain. In other words, a high concentration of unlabeled ligand would be required to saturate the binding of amyloid

TABLE 3

Kinetic Parameters Obtained by 2-Tissue-Compartment Model Analysis of ${ }^{11} \mathrm{C}-\mathrm{AZD} 2184$ Binding in AD Patients

\begin{tabular}{lcccccc}
\hline \multicolumn{1}{c}{ Brain region } & $K_{1}(\mathrm{~mL} / \mathrm{mL} / \mathrm{min})$ & $k_{2}\left(\mathrm{~min}^{-1}\right)$ & $k_{3}\left(\mathrm{~min}^{-1}\right)$ & $k_{4}\left(\mathrm{~min}^{-1}\right)$ & $V_{\mathrm{T}}(\mathrm{mL} / \mathrm{mL})$ & $D V R$ \\
\hline Frontal cortex & $0.21 \pm 0.04$ & $0.27 \pm 0.08$ & $0.09 \pm 0.02$ & $0.04 \pm 0.01$ & $2.49 \pm 0.48$ & $1.96 \pm 0.25$ \\
Temporal cortex & $0.22 \pm 0.05$ & $0.27 \pm 0.09$ & $0.08 \pm 0.01$ & $0.04 \pm 0.01$ & $2.48 \pm 0.43$ & $1.97 \pm 0.26$ \\
Parietal cortex & $0.18 \pm 0.05$ & $0.25 \pm 0.10$ & $0.07 \pm 0.02$ & $0.04 \pm 0.01$ & $2.30 \pm 0.47$ & $1.84 \pm 0.37$ \\
Occipital cortex & $0.28 \pm 0.05$ & $0.39 \pm 0.10$ & $0.07 \pm 0.02$ & $0.03 \pm 0.01$ & $2.35 \pm 0.54$ & $1.86 \pm 0.33$ \\
Hippocampus & $0.21 \pm 0.03$ & $0.32 \pm 0.08$ & $0.07 \pm 0.02$ & $0.04 \pm 0.02$ & $1.81 \pm 0.33$ & $1.43 \pm 0.15$ \\
Posterior cingulate & $0.26 \pm 0.06$ & $0.30 \pm 0.10$ & $0.08 \pm 0.02$ & $0.04 \pm 0.01$ & $3.04 \pm 0.77$ & $2.39 \pm 0.42$ \\
Centrum semiovale & $0.10 \pm 0.02$ & $0.14 \pm 0.03$ & $0.08 \pm 0.05$ & $0.05 \pm 0.03$ & $1.94 \pm 0.54$ & $1.51 \pm 0.22$ \\
Cerebellum & $0.28 \pm 0.05$ & $0.37 \pm 0.08$ & $0.03 \pm 0.02$ & $0.06 \pm 0.05$ & $1.27 \pm 0.20$ & -
\end{tabular}

Values are mean \pm SD. 
TABLE 4

SUVRs of ${ }^{11} \mathrm{C}-\mathrm{AZD} 2184$ in Control Subjects and AD Patients

\begin{tabular}{|c|c|c|c|c|c|c|c|c|}
\hline \multirow[b]{3}{*}{ Brain region } & \multicolumn{3}{|c|}{ Control } & \multirow[b]{3}{*}{$D V R$} & \multirow{2}{*}{\multicolumn{3}{|c|}{$\begin{array}{c}\text { AD } \\
\text { SUVR }\end{array}$}} & \multirow[b]{3}{*}{$D V R$} \\
\hline & \multicolumn{3}{|c|}{ SUVR } & & & & & \\
\hline & $20-40 \mathrm{~min}^{\star}$ & $40-60 \mathrm{~min}^{\star}$ & $60-90 \mathrm{~min}^{*}$ & & $20-40 \mathrm{~min}^{\star}$ & $40-60 \mathrm{~min}^{\star}$ & $60-90 \mathrm{~min}^{\star}$ & \\
\hline Frontal cortex & $1.04 \pm 0.04$ & $1.07 \pm 0.09$ & $0.99 \pm 0.10$ & $0.99 \pm 0.07$ & $2.16 \pm 0.28^{\dagger}$ & $2.17 \pm 0.27^{\dagger}$ & $2.13 \pm 0.28^{\dagger}$ & $1.96 \pm 0.25^{\dagger}$ \\
\hline Temporal cortex & $1.10 \pm 0.04$ & $1.14 \pm 0.04$ & $1.08 \pm 0.07$ & $1.07 \pm 0.06$ & $2.09 \pm 0.23^{\dagger}$ & $2.14 \pm 0.25^{\dagger}$ & $2.15 \pm 0.30^{\dagger}$ & $1.97 \pm 0.26^{\dagger}$ \\
\hline Parietal cortex & $1.06 \pm 0.07$ & $1.08 \pm 0.10$ & $1.03 \pm 0.09$ & $1.03 \pm 0.09$ & $1.93 \pm 0.30^{\dagger}$ & $1.98 \pm 0.38^{\dagger}$ & $2.01 \pm 0.44^{\dagger}$ & $1.84 \pm 0.37^{\dagger}$ \\
\hline Occipital cortex & $1.13 \pm 0.06$ & $1.21 \pm 0.08$ & $1.11 \pm 0.10$ & $1.12 \pm 0.09$ & $1.87 \pm 0.38^{\dagger}$ & $1.97 \pm 0.33^{\dagger}$ & $2.01 \pm 0.38^{\dagger}$ & $1.86 \pm 0.33^{\dagger}$ \\
\hline Hippocampus & $1.15 \pm 0.07$ & $1.18 \pm 0.05$ & $1.15 \pm 0.07$ & $1.11 \pm 0.07$ & $1.52 \pm 0.11^{\dagger}$ & $1.52 \pm 0.15^{\dagger}$ & $1.58 \pm 0.16^{\dagger}$ & $1.43 \pm 0.15^{\dagger}$ \\
\hline Posterior cingulate & $1.19 \pm 0.08$ & $1.24 \pm 0.13$ & $1.17 \pm 0.12$ & $1.16 \pm 0.11$ & $2.46 \pm 0.44^{\dagger}$ & $2.54 \pm 0.43^{\dagger}$ & $2.56 \pm 0.42^{\dagger}$ & $2.39 \pm 0.42^{\dagger}$ \\
\hline Centrum semiovale & $1.41 \pm 0.08$ & $1.49 \pm 0.14$ & $1.36 \pm 0.17$ & $1.30 \pm 0.12$ & $1.68 \pm 0.19$ & $1.72 \pm 0.21$ & $1.64 \pm 0.22$ & $1.51 \pm 0.22$ \\
\hline
\end{tabular}

*Integration interval.

${ }^{\dagger}$ Significant differences from normal control subjects (unpaired $t$ test, $P<0.01$ ).

Values are mean \pm SD.

radioligands to cerebral white matter (24). Moreover, it has been estimated that ROIs defined for the cerebral cortex contain about $60 \%$ of gray matter and $30 \%$ of white matter (25). This tissue heterogeneity may affect ${ }^{11} \mathrm{C}-\mathrm{AZD} 2184$ binding in the cerebral cortices.

To examine simplified approaches for quantification of ${ }^{11} \mathrm{C}$ AZD2184 binding, the SUVR was calculated using the cerebellum as a reference brain region, with integration intervals of 20-40, 40-60, and 60-90 min. The SUVR of each integration interval was at the same level and statistically in good agreement with the $D V R$ values obtained by kinetic analysis, although systemic overestimations in $S U V R$ were observed. This cross-validation indicates that ${ }^{11} \mathrm{C}-\mathrm{AZD} 2184$ binding can be estimated using a short scanning time and no arterial blood sampling. The nonlinearity and bias of $S U V R$ as compared with $D V R$ are observed in most radiotracers $(26,27)$. However, the fast relative equilibrium of ${ }^{11} \mathrm{C}-\mathrm{AZD} 2184$ could be one of the main advantages over ${ }^{11} \mathrm{C}$-PIB (4). In further study, systemic errors in SUVR of ${ }^{11} \mathrm{C}-\mathrm{AZD} 2184$ should be investigated with simulation studies. Although all integration intervals can be used to calculate $S U V R$, integration intervals of 40-60 and 60-90 min might be more preferable because the early part of the time-activity curve is generally affected by changes in $K_{1}$ due to changes in cerebral blood flow (20). However, a lack of an early phase of PET data might hamper an adequate coregistration between PET and MR images, especially in control subjects because of a low binding in the white matter.

It has been reported that synaptic loss is associated with nondiffuse plaques, but not with diffuse plaques (28), and that the neuropathology in $\mathrm{AD}$ is characterized by cortical neuritic plaque containing dense-cored amyloid deposition (29). ${ }^{11} \mathrm{C}$ $\mathrm{BF} 227$, a recently developed radiotracer for in vivo imaging of amyloid- $\beta$, has been considered to bind more preferentially to dense-cored amyloid deposition than ${ }^{11} \mathrm{C}-\mathrm{PIB}$ (19). Further research is needed to demonstrate the binding characteristics of ${ }^{11} \mathrm{C}-\mathrm{AZD} 2184$ in different types of amyloid plaque.

\section{CONCLUSION}

The novel radioligand ${ }^{11} \mathrm{C}$-AZD2184 provides high-contrast imaging of amyloid- $\beta$ deposits in brain. The regional kinetics of ${ }^{11} \mathrm{C}$ AZD2184 binding in control subjects and AD patients could be described by the standard 2-tissue-compartment model. The $S U V R$ calculated from integrated time-activity curves in targeted and reference brain regions can be used as an index of ${ }^{11} \mathrm{C}$ AZD2184 binding for clinical investigations without arterial input function.

\section{DISCLOSURE}

The costs of publication of this article were defrayed in part by the payment of page charges. Therefore, and solely to indicate this fact, this article is hereby marked "advertisement" in accordance with 18 USC section 1734. This study was supported in part by the "Japan Advanced Molecular Imaging Program (J-AMP)" of the Ministry of Education, Culture, Sports, Science and Technology (MEXT), Japanese Government, and a grant-in-aid for Comprehensive Research on Dementia (no. 11103404) from the Ministry of Health, Labor and Welfare. No other potential conflict of interest relevant to this article was reported.
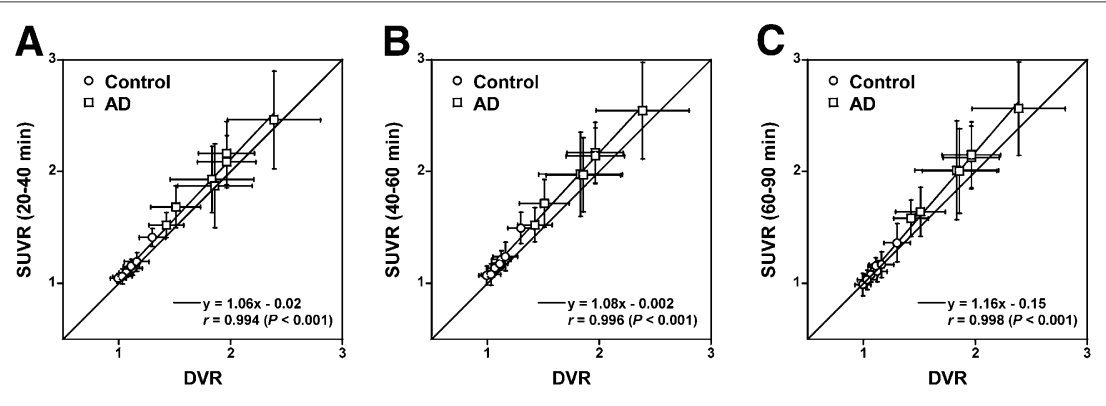

FIGURE 7. Relationship between DVR and SUVR for integration intervals of 20-40 min (A), 40$60 \mathrm{~min}(\mathrm{~B})$, and 60-90 min (C). Respective data indicate mean and SD of each ROI.

\section{ACKNOWLEDGMENTS}

We thank Katsuyuki Tanimoto, Takahiro Shiraishi, Kazuko Suzuki, and Izumi Izumida for their assistance in the PET experiments. 5-(6-\{[tert-butyl(dimethyl)silyl] oxy $\}-1,3-$ benzothiazol-2-yl)pyridin-2-amine (AZD2184) and its precursor 5-(6-(tert-butyldimethylsilyloxy)benzo[d]thiazol-2-yl)pyridin-2-amine were kindly provided by AstraZeneca R\&D, Södertälje, Sweden. 


\section{REFERENCES}

1. Braak H, Braak E. Neuropathological stageing of Alzheimer-related changes. Acta Neuropathol. 1991;82:239-259.

2. Hardy JA, Higgins GA. Alzheimer's disease: the amyloid cascade hypothesis. Science. 1992;256:184-185.

3. Mathis CA, Wang Y, Holt DP, Huang GF, Debnath ML, Klunk WE. Synthesis and evaluation of ${ }^{11} \mathrm{C}$-labeled 6-substituted 2-arylbenzothiazoles as amyloid imaging agents. J Med Chem. 2003;46:2740-2754.

4. Klunk WE, Engler H, Nordberg A, et al. Imaging brain amyloid in Alzheimer's disease with Pittsburgh compound-B. Ann Neurol. 2004;55:306-319.

5. Choi SR, Golding G, Zhuang Z, et al. Preclinical properties of ${ }^{18} \mathrm{~F}-\mathrm{AV}-45$ : a PET agent for A $\beta$ plaques in the brain. J Nucl Med. 2009;50:1887-1894.

6. Johnson AE, Jeppsson F, Sandell J, et al. AZD2184: a radioligand for sensitive detection of beta-amyloid deposits. J Neurochem. 2009;108:1177-1186.

7. Nyberg S, Jonhagen ME, Cselenyi Z, et al. Detection of amyloid in Alzheimer's disease with positron emission tomography using [ $\left.{ }^{11} \mathrm{C}\right]$ AZD2184. Eur J Nucl Med Mol Imaging. 2009;36:1859-1863.

8. McKhann G, Drachman D, Folstein M, Katzman R, Price D, Stadlan EM. Clinical diagnosis of Alzheimer's disease: report of the NINCDS-ADRDA Work Group under the auspices of Department of Health and Human Services Task Force on Alzheimer's Disease. Neurology. 1984;34:939-944.

9. Morris JC. The Clinical Dementia Rating (CDR): current version and scoring rules. Neurology. 1993;43:2412-2414.

10. Folstein MF, Folstein SE, McHugh PR. "Mini-mental state": a practical method for grading the cognitive state of patients for the clinician. J Psychiatr Res. $1975 ; 12: 189-198$.

11. Andersson JD, Varnas K, Cselenyi Z, et al. Radiosynthesis of the candidate betaamyloid radioligand $\left[{ }^{11} \mathrm{C}\right] \mathrm{AZD} 2184$ : positron emission tomography examination and metabolite analysis in cynomolgus monkeys. Synapse. 2010;64:733-741.

12. Matsumoto K, Kitamura K, Mizuta T, et al. Performance characteristics of a new 3-dimensional continuous-emission and spiral-transmission high-sensitivity and high-resolution PET camera evaluated with the NEMA NU 2-2001 standard. J Nucl Med. 2006;47:83-90.

13. Ishikawa A, Kitamura K, Mizuta T, et al. Implementation of on-the-fly scatter correction using dual-energy window method in continuous 3D whole body PET scanning. IEEE Nucl Sci Symp Conf Rec. 2005;5:2497-2500.

14. Mintun MA, Raichle ME, Kilbourn MR, Wooten GF, Welch MJ. A quantitative model for the in vivo assessment of drug binding sites with positron emission tomography. Ann Neurol. 1984;15:217-227.

15. Innis RB, Cunningham VJ, Delforge J, et al. Consensus nomenclature for in vivo imaging of reversibly binding radioligands. J Cereb Blood Flow Metab. 2007;27: 1533-1539.
16. Marquardt D. An algorithm for least-squares estimation of nonlinear parameters. J Soc Ind Appl Math. 1963;11:431-441.

17. Ito H, Ota M, Ikoma Y, et al. Quantitative analysis of dopamine synthesis in human brain using positron emission tomography with $\mathrm{L}-\left[\beta-{ }^{11} \mathrm{C}\right] \mathrm{DOPA}$. Nucl Med Commun. 2006;27:723-731.

18. Price JC, Klunk WE, Lopresti BJ, et al. Kinetic modeling of amyloid binding in humans using PET imaging and Pittsburgh compound-B. J Cereb Blood Flow Metab. 2005;25:1528-1547.

19. Kudo Y, Okamura N, Furumoto S, et al. 2-(2-[2-dimethylaminothiazol-5-yl] ethenyl)-6- (2-[fluoro]ethoxy)benzoxazole: a novel PET agent for in vivo detection of dense amyloid plaques in Alzheimer's disease patients. J Nucl Med. 2007;48:553-561.

20. Ito H, Hietala J, Blomqvist G, Halldin C, Farde L. Comparison of the transient equilibrium and continuous infusion method for quantitative PET analysis of $\left[{ }^{11}\right.$ C]raclopride binding. J Cereb Blood Flow Metab. 1998;18:941-950.

21. Klunk WE, Wang Y, Huang GF, et al. The binding of 2-(4'-methylaminophenyl) benzothiazole to postmortem brain homogenates is dominated by the amyloid component. J Neurosci. 2003;23:2086-2092.

22. Klunk WE, Lopresti BJ, Ikonomovic MD, et al. Binding of the positron emission tomography tracer Pittsburgh compound-B reflects the amount of amyloid-beta in Alzheimer's disease brain but not in transgenic mouse brain. J Neurosci. 2005;25:10598-10606

23. Fodero-Tavoletti MT, Rowe CC, McLean CA, et al. Characterization of PiB binding to white matter in Alzheimer disease and other dementias. J Nucl Med. 2009;50:198-204.

24. Stankoff B, Freeman L, Aigrot MS, et al. Imaging central nervous system myelin by positron emission tomography in multiple sclerosis using [methyl- $\left.{ }^{11} \mathrm{C}\right]-2-\left(4^{\prime}-\right.$ methylaminophenyl)- 6-hydroxybenzothiazole. Ann Neurol. 2011;69:673-680.

25. Ito H, Takahashi H, Arakawa R, Takano H, Suhara T. Normal database of dopaminergic neurotransmission system in human brain measured by positron emission tomography. Neuroimage. 2008;39:555-565.

26. Ito $\mathrm{H}$, Halldin $\mathrm{C}$, Farde L. Localization of $5-\mathrm{HT}_{1 \mathrm{~A}}$ receptors in the living human brain using [carbonyl- ${ }^{11} \mathrm{C}$ ]WAY-100635: PET with anatomic standardization technique. J Nucl Med. 1999;40:102-109.

27. Zhou Y, Sojkova J, Resnick SM, Wong DF. Relative equilibrium plot improves graphical analysis and allows bias correction of standardized uptake value ratio in quantitative ${ }^{11} \mathrm{C}-\mathrm{PiB}$ PET studies. J Nucl Med. 2012;53:622-628.

28. Masliah E, Terry RD, Mallory M, Alford M, Hansen LA. Diffuse plaques do not accentuate synapse loss in Alzheimer's disease. Am J Pathol. 1990;137: 1293-1297.

29. Price JL. Diagnostic criteria for Alzheimer's disease. Neurobiol Aging. 1997;18: S67-S70. 